
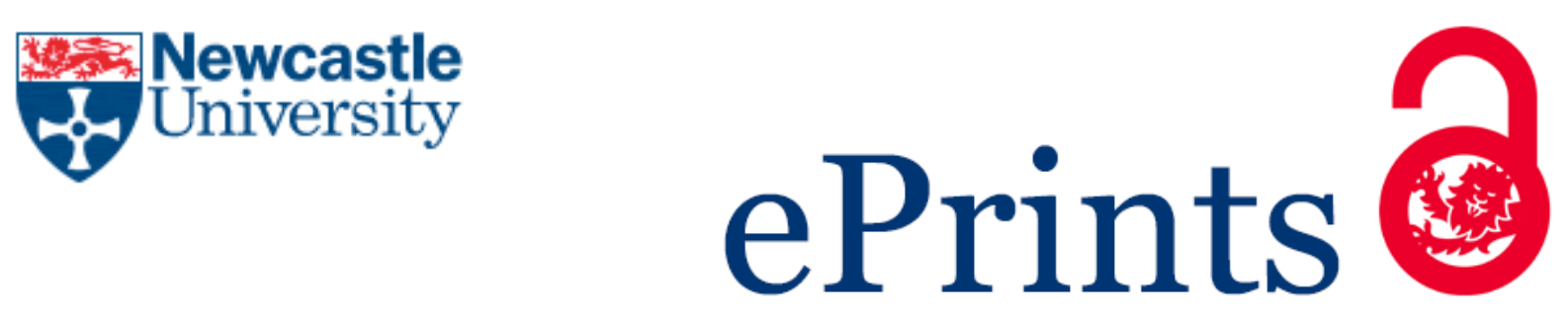

Townsend J, Laurie N, Poudel M, Richardson D. (2015)

Gender, post-trafficking and citizenship in Nepal.

In: Coles, A., Gray, L. and Momsem, J. (eds.)

Routledge Handbook of Gender and Development.

London: Routledge, pp.319-329.

Copyright:

This is an Accepted Manuscript of a book chapter published by Routledge in Routledge Handbook of Gender and Development on 19/02/2015, available online:

http://www.routledge.com/books/details/9780415829083/

Date deposited:

$12 / 12 / 2014$

Embargo release date:

19 August 2016

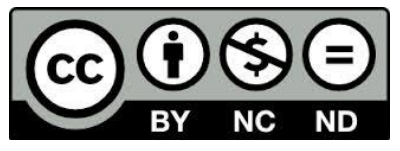

This work is licensed under a

Creative Commons Attribution-NonCommercial-NoDerivatives 4.0 International licence 


\section{Gender, post-trafficking and citizenship in Nepal}

Janet G. Townsend, Nina Laurie, Meena Poudel and Diane Richardson

\section{Introduction}

The United Nations High Commission for Refugees (UNHCR, 2013, Stateless people p.1) estimates that 'Statelessness is a massive problem that affects an estimated 12 million people worldwide'i. In many parts of the world many people, women in particular, are still non-citizens, so that basic legal, political and/or welfare rights have not yet been attained. Exclusionary policies lie at the root of many statelessness situations. We argue here that citizenship has widely been constructed in a male image, because for women access to citizenship has historically been linked to motherhood in the context of heterosexual marriage. A new literature linking the discourses of citizenship, development and sexualities has appeared, but such debates must be situated within particular socio-economic and geopolitical contexts: case studies are needed.

Our case study is with a number of women in Nepal: 'returnees' or 'survivors', women who have been trafficked, usually for sexual purposes, to India or beyond and have managed to return to a difficult situation. The Nepal census of 2011 reported a population of $26,849,041^{i i}$. Nepal still has problems of statelessness, particularly regarding citizenship. Even though it achieved in 2007 the largest reduction of statelessness the world had seen, issuing nationality to 2.6 million people after the end of the civil war (1996 - 2006), Nepal may still host some 800,000 people whose nationality is not confirmed and who cannot, without a citizenship certificate, access important government services or secure their human rights (UNHCR, 2013). From May to July 2013, all political parties advocated the granting of citizenship along with voter registration for elections in November for a new 
Constituent Assembly (to write a new Constitution for Nepal and also to act as government). This included a massive campaign to encourage younger people.

In this chapter, we shall introduce our project and describe our case study: the problems of stigma for returnee trafficked women as a hindrance to livelihoods and citizenship, and the complexities surrounding livelihoods and professionalization. We shall not deal with trafficking itself, rather our research examines livelihood opportunities for trafficked women on return to their home country. This was a collaborative project between Shakti Samuha, a Nepali NGO (nongovernment organization) working with trafficked women, Newcastle University, UK ${ }^{i i i}$ and the International Organization for Migration in Nepal.

We shall see that many women who return to Nepal from trafficking, to India, the Middle East or Southeast Asia are rejected by their families and their communities. If they do not already have citizenship, this may mean that they are stateless since recommendation by a male relative has traditionally been necessary. Again, we shall see that those who lack citizenship may be excluded not only from education, health, legal assistance and training but from many jobs. In practice (Richardson. et al. (under review)), this is still likely to be the case even though 'mother and father' (but not 'or', so that mother alone cannot recommend) are technically now named in law for the recommendation. Returnee women therefore have a desperate need for livelihoods, but very few are available without the support of their families. Unfortunately, the emphasis of Western donors in anti-trafficking is on the roles of the police and the courts, so the vital long-term goal of lobbying for systematic and structural changes in society gets overlooked. We shall not develop this further here. We shall conclude that comprehensive change from within Nepali society is needed not just to reduce trafficking but to support the rights of returnees (compare Bennett, 2008 p.218). We shall argue above all that citizenship and livelihoods are fundamental to these rights. 
There has been little research on post-trafficking livelihoods, or on their place in development. Our goals were to secure knowledge well-grounded in the lives of women returnees, and to emphasise the voices of these women. This agenda follows our partnership with Shakti Samuha, which is now one of the leading anti-trafficking organisations in Nepal and the only NGO in South Asia, and possibly the world, founded and run by returnee trafficked women (GAATW 2007) ${ }^{\text {iv }}$. Shakti Samuha are deeply proud of their foundation story ${ }^{v}$ as we see here. In 1996,

'148 Nepalese girls and women were rescued from slavery in Indian brothels during widespread police raids... These women were then locked away in remand homes in India, where conditions were as bad as - if not worse - than prison. The Nepalese government was reluctant to bring the women back to Nepal, claiming they would bring HIV into the country with them.'

Shakti Samuha also report that NGOs in Nepal took the lead in returning and rehabilitating the girls. Sadly, even in these rehabilitation centres, the women's treatment did not help to restore their self-esteem and basic human rights. Only after months had passed and they had training in their rights did they realize they were not to blame for being trafficked. The women felt it was time to claim their rights, so they set up Shakti Samuha.

Shakti Samuha has built up counselling, support and training, grounded in their personal experiences. They feel that their approaches are more appropriate in design and delivery than those of other NGOs. Having been trafficked themselves, they claim to know better what is needed. They work to challenge discourses of victimization, seeking rights of citizenship and to chosen livelihoods for trafficked women. To a degree, by organising themselves and other trafficked women, they have changed many Nepali trafficked women's understanding of themselves and their society (Richardson et al., 2009). We need to 
remember, "a woman's life is richer than her trafficking experience" (Rapier-Moore, 2012 p. 231).

We explore through returnee women's livelihood strategies the intersectionalities of sexuality, gender, citizenship and development. Nepal elected a Constituent Assembly in 2007 to rewrite the national Constitution, which includes citizenship as a fundamental right. Our project's collaborative partnership and the emerging findings have been used to lobby the Constituent Assembly process, organizing workshops and meetings to discuss the challenges facing returnee women without citizenship. The Assembly was disbanded by the Supreme Court in May 2012, leaving the revised Constitution incomplete and the future of citizenship uncertain pending fresh elections (eventually November 19 2013).

\section{Case study}

This case study is based on analysis of interviews given generously by returnee trafficked women and by stakeholders in anti-trafficking organizations. To reach the experiences of the trafficked women themselves and respect the sensitivity of the issues, our research methods were qualitative. We conducted 46 interviews with returnee trafficked women from urban and semi-rural locations identified in the past by government for high occurrences of trafficking. Overall, we selected women with differing degrees of engagement with NGOs and social movements and who self-identified as returnee trafficked women. They range from 17 to 44 years of age, from eight caste/ethnic social groups and four religious backgrounds. They represent different local home regions, returnee routes and timeframes of return; ages of being trafficked/returned; ethnicities and castes; length/number of trafficked journeys; and access to citizenship.

Nepal's census of 2011 enumerated 125 ethnic/caste groups and 123 languages. Of the Hindu population, Brahmins and Chhetris were in 2001 officially clustered as upper castes and were widely distributed across the country. Their language is Nepali, and in 2001 they 
were 39 per cent of Nepal's population. Dalits, also Hindu (once "untouchables" and still suffering discrimination) are officially clustered as lower castes, and live in the hills/mountains and the terai/lowlands. In 2001 they were around 40 per cent of the population. Ethnic/indigenous groups in our sample are mainly Buddhist Tibeto-Burman. They include the indigenous groups of i) the Magar, along the southern edge of the Himalaya, following Buddhism/Hinduism ii) the Tharu, indigenous to the Terai, the southern foothills of the Himalayas across into India, almost all Hindus iii) the Tamang, in the entire mountainous region, mainly Tibetan Buddhists iv) the Sherpas, also Tibetan Buddhists, in the most mountainous area v), the Rai, in the eastern foothills, Hindu/Buddhist. The actual pattern is extremely complex, and in many areas religions may shade into each other; households may even call on different priests for different rituals.

We started recruiting and selecting subjects from NGOs and then used snowballing techniques to reach women without current, direct NGO contact. In our first analysis of an initial set of 37 interviews, professionalization (see below) emerged as a theme, so a further nine were conducted specifically with returnee trafficked women involved as activists/professionals in anti-trafficking. We held a further 14 stakeholder interviews with other activists, key personnel in NGOs, donors and government. Through these interviews we explored discourses and emerging policies on trafficking and citizenship in Nepal and internationally, and tracked the evolution of debates in the Constituent Assembly. The interviews examined returnee women's own experiences and assessments of the strategies that enable women to exit (or not) from trafficking and prostitution, including passing as 'migrant workers'. They gave us their evaluation of the significance of a range of factors including local contacts, social capital, and skills-training. Interviews were taped and transcribed in Nepali (or in a few cases ethnic dialects), and then translated into English. Interview transcripts use the idiom of the original translation as we wish to recognise that 
Nepali English is one of many forms of global English that is spoken. All names in the paper are pseudonyms.

Kathmandu, the capital, is where government policies are formed and decisions taken; it is the hub for domestic and international transport; it is here that the majority of returnee women settle. The three locations selected outside Kathmandu are all extremely poor. Meena Poudel, the Nepali member of the team, conducted the 37 initial interviews with returnee trafficked women, given the sensitive nature of the discussion and her fluency in most Nepali languages and dialects. Other members of the team then took part in interviews with the returnee trafficked activists/professionals, and the stakeholders (donors, civil servants and anti-trafficking NGOs other than Shakti Samuha). A leading theme of the interviews was stigma (see Poudel 2011) where the attachment of even a suspicion to a woman of having been trafficked is a serious constraint, which may lead to social isolation, loss of confidence, depression and deprivation. Materially, the stigma may painfully limit possible livelihoods, our second theme, through her being rejected for work as impure. Our third theme is the professionalization of work, which might provide opportunities, but where social exclusion and limited opportunities can be problems. Our fourth is citizenship, where government officials may reject a woman suspected of having been trafficked.

\section{Stigma}

In Nepal, izzat, the honour of a man or a family, is in the hands of its women; 'women's sexuality...can compromise the pedigree of an entire household or lineage' (Rankin, 2004:148). Nepal was the world's last constitutionally declared Hindu state but after the movement for democracy the Nepali Parliament amended the constitution to make Nepal a secular state. Questions of honour still surround trafficked women on their return, across the very diverse Nepali cultures. The 2011 census reports the Nepalese population as 81.3 per cent Hindu, 9.0 per cent Buddhist, 4.4 per cent Muslim, 3.0 per cent Kirant/Yumaist (an indigenous religion) and 1.4 per cent Christian ${ }^{\text {vi }}$. In the (Hindu) Newar culture ${ }^{\text {vii }}$ a 
household's honour accrues not only by maintaining social investments but by managing the sexuality and ritual purity of its women (Rankin, 2004). In a Hindu upper-caste settlement studied by Lynn Bennett (1983) for ten years, the patrilineal system stressed the sacredness of daughters and other blood-related women, and ritual purity dominated women's lives, from confinement to an outdoor shed during menstruation to being responsible for most of the ritual activities of the household. Most Tamang, on the other hand, are Buddhist. Nepali views on purity vary greatly between ethnic groups and religions, but we found that Hindu norms applied widely to trafficked women, so that many Hindu, Tamang or Christian posttrafficked women suffer deeply from stigma. In most places, a woman who is trafficked, however unwillingly, is labelled as a prostitute (and in some cases as an 'AIDS carrier'; in our interviews, nine women said they came back from trafficking HIV positive). It is as if many post-trafficked women are rejected by their families, their communities and their government. We discuss their occupations in Nepal under livelihoods below. We sought to avoid their revisiting the trauma of their varied experiences abroad, partly because ESRC would have required us to have had specialised help on hand if questions caused distress.

One woman said that people think trafficked women are bad, chhada (out of control), and may 'spoil' other women. Another woman, Nisha, was asked whether she could work and feed herself since returning from trafficking, but said no, there were problems. "For example, the boss at work place trying to misconduct with us; not providing us salary...trying to do jabarjasti [force to have sex] and balatkar [rape]."

Stigma surrounds trafficked women with sources of pain. They are clearly victimised in many different ways. For some, even though society may remain difficult, a shift in their attitude helps.

Dimi: I see myself as a trafficked woman but sometimes I forget the fact...Five years ago I saw no way in front of me. I was in a condition of dying, felt like already a dead 
person. For me, life was over; life was finished...Now I think trafficking is not a big issue, just your attitude, just your thinking. I am a human being more than a trafficked woman. Now I feel I am something and I can do something in life.

Dimi put this achievement down to Shakti Samuha's kindness, counselling and training. Most of our interviewees valued Shakti Samuha very highly for their warmth and effectiveness, first in refuges, later in counselling, training and finding employment.

One escape from stigma may be marriage, which may also lead to citizenship and possibly livelihood (Richardson et al., 2009). Many women interviewed, however, live with situations of extreme abuse from their husbands, which raises questions about how sustainable marriage is in the long term as a way of coping with stigma.

Ramila: My husband is aware of it [her trafficking history]. He because of this knowledge also gives me much torture [emotional in tone]. He knows it. I told him prior to marriage.

\section{Livelihoods?}

Returnee trafficked women are one of the most stigmatised, marginalised, excluded and vulnerable groups in Nepal, yet rights to sustainable livelihoods have become a rallying point for lobbying activities. Individual women look to the labour market as some escape from stigma and poverty. NGOs play an important role in skills training. Many of these skills are traditional jobs for women like cooking, carpet making, sewing or tailoring. From our interviews, however, these jobs seldom generate enough income to provide sustainable livelihoods. One problem is that many of the women have had little education. Many were fully occupied in childhood. At the age of eight, Usha provided casual labour for other farmers, carrying water, cutting grass for feed, cleaning up the cow dung, taking the goats out for grazing. Other poor women have similar backgrounds, but exclusion after trafficking adds greater difficulties. As Usha said, 'Back then, it was not common to send the 
daughters to school. It was only for boys then... it was out of question with no place to stay and no food to eat...how can we think of education?"

Poverty is a key factor in the lives of post-trafficked women. For commentators such as Lynn Bennett (2008 p. 218), poverty reduction will not be achieved without culture change, which is very slow and ebbs and flows. In 1983, Bennett reported on her anthropological work in the 1970s, the goal of which was to interpret the Hindu perception of women in one village. This is now a classic study and gives her a very valuable perspective. For Bennett now, bedrock Hindu values continue to structure the worldview of most Nepalis, of all religions. She calls instead for more emphasis on Hindu egalitarian strands, for human rights to be reflected in law and practice and for corruption to become unacceptable. She emphasizes that specific, desired, cultural changes cannot be induced by anyone and certainly not by outsiders (Bennett, 2008), thereby highlighting further the work of national activists and NGOs such as Shakti Samuha who both support individual women and provide an important lobbying role in the country. For Shakti Samuha, livelihoods and citizenship are central to solutions.

Today, some NGOs provide start-up loans for women launching their own businesses, including 'non-traditional' occupations such as driving 'tempos' (moto-rickshaws) or working as plumbers or electricians. They also provide basic business training. It appears that women can earn more in jobs such as driving or working as security guards, but some nontraditional occupations are better options than others. These are typically male occupations and may present work-place prejudice for women. A plumber or electrician needs to go into people's homes to work, and to build up a client base. For a returnee woman this threatens challenges for confidence and personal safety, and for outsiders, Nepali or foreign, it is not easy to know where danger lies. For example, while a traditionally female workplace, carpet 
factories have historically been a source of recruiting young girls into trafficking (Samarasinghe, 2008).

Similarly, computing, a 'modern' job in which skills training is being provided by NGOs, seems alarming to some, as Jyoti explains:

Jyoti: We also learnt computer for four month in Pokhara Vocational Training Centre where I had received training [on the advice of Shakti Samuha] but computer I could not practice.

Question: Why?

Jyoti: Because computer I think was something, easy skill for men because if you go to computer places, you see many men practising and few women, but if you see beautician you see many women and very few men. Also what I feel is even if I do computer work with a group of men/boys I fear that I will be unsafe.

Personal safety is indeed an issue. Returnee women feel seen as more available for sex than others:

Nirmala: I had to struggle a lot to get work; I used go to the offices [including Coca Cola] directly to look for a job. They used to make direct proposals that if I stayed there for the night, he would get me a job. I thought instead of making money that way, I would rather return back to the village. I did not pay attention to their advances.

Other poor women also suffer from sexual harassment in employment, but returned trafficked women seem to feel rendered more vulnerable by their experiences.

Returned trafficked women refer to themselves as survivors, not victims. Preeta, a senior 
manager at a major international foundation with wide experience and understanding. has outspoken views on the strength of many returned trafficked women:

We have to realize: we don't have to train people on mechanics, electronics or mainstream job. We have to depend on outside institutions to do that. We have to have links with mainstream technical institutions, colleges and vocational training centre. We should be able to push them to accept those girls. We need to move these young people or girls to start getting training in institutions which are absorb in the mainstream rather than giving skills inside the home or inside the shelter [refuge].... A woman who has been into a sex industry and who has worked as prostitute or has been trafficked has much skills stronger than any of us do because she survived the extreme circumstances and probably knows better (emphasis added).

\section{Professionalization?}

One answer for livelihoods is professionalization. Some members of Shakti Samuha become staff in that NGO, with work from cooking or cleaning to counselling, awareness-raising or running hostels to serving on the Executive Board of Shakti. Kathmandu has a remarkable concentration of NGOs, including many anti-trafficking which are mainly charitable, not developmental. Donor support (from bilateral, multilateral and charitable sources) has led to a growing demand for staff.

For members of Shakti Samuha, working for their NGO is a popular option, as Nisha shows.

Nisha: I think to continue the work, what I am doing now. I think on working on awareness against trafficking, organizing, as much as possible involving teens, other communities wherever we are working, publicizing about trafficking, trafficking and violence, making this success and working in trafficking continuously...It is difficult for filling stomach. It is expensive in place like Kathmandu, after having baby there is 
so much of expenses involved with baby, have to pay for room rent, that is creating so much of difficulty...Whatever opportunities Shakti Samuha is providing for affected [trafficked] women, to members of the organizations and they are providing much facilities, support for income generation to them, job support for them, if they don't have any provision keep them in their hostel and manage food and clothes, if they want to go to home make a conducive environment for reintegration, it does all these, here they do counselling, there is so much, there are friends, and feel relaxed. Staying in hostel, providing trainings, jobs before they leave. I feel satisfied in this.

Nearly all the staff of Shakti Samuha are returnee trafficked women, including the Executive, which is elected every two years. Some have gone through exacting training schemes. Some professional jobs requiring specialist training, such as finance, have been filled from outside the organization, creating tensions. When we asked Shakti members if they would be willing to work for other NGOs, they replied that while other anti-trafficking NGOs also employ returnee women, they employ them as staff, while Shakti Samuha employs them as members with voices in the organization.

Professionalization is a vexed question, involving questions of power. Shakti Samuha has a substantial staff, and a commitment to training and educating them, as far as possible to their full potential. For Shakti Samuha, education to become a professional is a strategy for overturning discriminatory social hierarchies. They reject the neoliberalism of many of Kathmandu's NGOs where hierarchies of knowledge are produced and discrimination and social exclusion reproduced. Shakti Samuha argue that they value merit. As a test of the outcome, we can look at the caste/ethnicity of our returnees. 14 of 46 were upper caste, 10 Dalit, 11 Tamang, four Magar, three Rai, three Tharu, one Sherpa. Of the Executive Board members in 2012, five were hill ethnic/indigenous, two Dalit, two Terai ethnic and one upper caste. There may be no reproduction of social discrimination. If only Shakti Samuha's tenets 
were more widely held, non-neoliberal professionalization would be an option for many more returnee women.

As a part of our collaboration, we asked Shakti Samuha what other dimensions of support they would like to emerge. They asked for training in research methods so that they could do their own research; this was subsequently provided through a modular course delivered by Nepali specialist academics to Shakti's Executive. Kamala is an Executive member.

Kamala: Research has been very important to understand the jeevan ra jagaat (life and the world), social world we live in. We have been involved in research work through consultancy and all but it is very important to take the research training once in life. I have realized this importance of research training after I took it. I don't know whether I would be able to sustain my livelihoods being a researcher or not but taking this training is very important. Shakti has been doing research funded by other donors and recruiting researchers for us. But this is us doing research for ourselves and it is very important to analyze our social world from our perspectives.

The final stages of the training programme involved the design of a free-standing research project by Shakti Samuha which at the time of writing is in progress, focussed on the social impact of the legal process. Very few cases are actually filed in court against traffickers. What is the women's experience? Trafficking survivors are the researchers in this project and will share the feelings of survivors who have gone through legal cases. Ethics are a major concern and have been considered very thoroughly. It is thought that there are so few cases because of the fear and reality of harm to the survivors. Safety is the first consideration. This enquiry will follow the World Health Organization Ethical and Safety Recommendations for Interviewing Trafficked Women (WHO 2003) which highlight ‘Do no Harm' strategies to avoid re-traumatizing trafficked women (see above) 
Shakti Samuha's leading goals are citizenship and livelihoods for their members and other women. Citizenship emerged as a core focus in our collaborative work.

\section{Citizenship}

Young men and women may apply for citizenship from the age of 16 (Richardson et al. under review). Both can acquire citizenship through recommendation, but in practice, young women need fathers or other male relatives to recommend them. Many were trafficked too young to be 'citizens' then. On return, many male relatives refuse to recommend them for citizenship, feeling that these women have dishonoured the family. In our sample, just over two-thirds of the women did not have citizenship when they were trafficked. Of those who did have citizenship, almost all obtained it with the support of their fathers, husbands or male relatives, at least nine before trafficking and fourteen after. Six of our sample did not have citizenship at the time of the interviews. There is little tradition of registering of births and the border with India is open, facts which present problems of evidence of birthplace. At present a Nepali woman's citizenship (if any) allows her to live, work, vote and spend money in Nepal, but does not allow her to pass those rights to her children. DfID and the World Bank (2006, p.26) call for equal rights to citizenship for women and men in Nepal. Lynn Bennett discusses the proposed policies of these agencies from the same project, see above $(2008$, p..218, 222).

Citizenship is highly valued by returnee women, and they are vocal on the subject. It is difficult to find a room to rent without it. This represents a "class" divide in access to livelihoods. "There is no work without citizenship" (Sabita and others). In practice many women work without citizenship, but much of that work is unskilled, say in agriculture, cleaning or brickworks. Citizenship is likely to be needed to access government services, including health, education and training, obtaining a marriage certificate, registering a birth, the right to vote and the right to a passport. 
Rupa: He can say that my children are not his. In that situation marriage certificate is useful [citizenship is needed for marriage certificate or certificate of birth].

Citizenship is also fundamental in supporting women who are attempting to claim property rights. Uma, a returnee who is seeking such rights, said "If you don't have Nepali citizenship you don't have identity." In Nepal, most inheritance systems emphasise patrilineal descent and patrilocal residence (less so among the Tamang). This effectively places restrictions (that do not apply to men) on a woman's rights to inheritance of her and her husband's property, or, if unmarried, from her natal family (Rankin 2004; Samarasinghe, 2008). These laws on property rights are important for women seeking citizenship from male relatives who have a vested interest in them remaining non-citizens, not least where denying a woman proof of citizenship may be 'justified' as being for the collective good through maintaining the family honour (Richardson et al. under review). Citizenship has been a major field for advocacy for Shakti Samuha, involving their paid staff and members who volunteer.

Question: How does stigma attached to being trafficked shape access to citizenship? Sabita: It affects all our lives...in my case, my family supported me so it [citizenship] happened, but in other friends' case, it is really difficult.

With Shakti Samuha, we organized two workshops with activists in Kathmandu. The first, in February 2011, brought together 80 participants including leading anti-trafficking NGOs, Nepali government representatives, donors and key members of the Constituent Assembly including the head of the Fundamental Rights Committee who used case study material from the workshop in press releases. Thirty trafficked women survivors also attended. Extensive media coverage followed this event, including interviews on Nepali TV stations (which are distributed to the diaspora internationally through the web) and radio station interviews, as well as print articles in the Nepali press. The second workshop, a highly successful research seminar, was held on November $4^{\text {th }} 2011$ to disseminate preliminary findings from the 
analysis of the interviews conducted with returnee trafficked women. This was opened by the Minister for Women, Children and Social Welfare and attracted more than 100 participants, including several members of the Assembly and senior policy makers. More media coverage followed. On 11 $1^{\text {th }}$ March 2012, we took part in a DfID UK Anti-Trafficking Stakeholder Meeting in London, along with representatives from six DfID pilot projects and civil servants from DfID and the UK Treasury viii.

Nepali feminist, human rights and anti-trafficking activists challenged citizenship provision in the then-proposed new Constitution, arguing that citizenship for women and men should be granted based on birth in the country of Nepal, with the proviso that, until such changes occur, mothers or fathers should be able to confer citizenship by descent. Children born abroad to sexually exploited mothers but now living in Nepal should be granted citizenship based on state endorsement. Our findings indicated that this is a model of citizenship that many post-trafficked women thought should be adopted.

Even for women who do have formal citizenship, the patriarchal nature of Nepali society (Rankin, 2004; Samarasinghe 2008; Richardson under review) renders them unequal citizens in many respects. They also demand equal rights to inheritance, property and land, education and healthcare, non-discriminatory laws on travel and migration and much more legislation and action to eliminate violence against women. At least one woman in our sample had been raped and impregnated by police when she went to report her trafficking: very large changes are needed.

In 2011, Nepal's Supreme Court ruled in support of provision that mothers as well as fathers could confer citizenship on their children but in practice there would appear to be resistance to implementing this. With regard to naturalization and the requirement for foreign men to live 15 years in Nepal to achieve it, it is suggested that this reflects geopolitical securitisation 
fears about the open border with India and the potential that changing citizenship laws could make Nepal vulnerable to Indian interests.

\section{Elections}

Elections for the Government and Constituent Assembly that took place on November $19^{\text {th }}$ 2013 attracted more than 70 per cent of the 12 million eligible voters to cast their votes. In 1990/91, 9 women were elected out of 205 seats; 2006, 30 women out of 240; but 2013, 10 out of 240. In 2008, the Maoists (now United Maoists), won the largest number of votes, but this time they failed to secure an outright majority. Pushpa Kamal Dahal, better known as Prachanda, their leader, claimed a "conspiracy" and called for a recount, but it was refused. (He lost his Kathmandu seat ${ }^{\mathrm{ix}}$, but won a seat in Siraha, southern Nepal ${ }^{\mathrm{x}}$.) No party has a clear majority, so a government is not expected to be formed for several weeks ${ }^{\mathrm{xi}}$. Without the United Maoists, who have threatened to boycott the CA, the CA process and change agendas may not advance. Analysts say the moderate politicians who triumphed will struggle to form a stable government and write a new constitution. ${ }^{\text {xii }}$

\section{Conclusion}

At the time of writing, any improvement in the access to citizenship of returnee trafficked women and of millions of other Nepali women without passports is delayed or ended. But the draft constitution was saved in the CA secretariat and will, we hope, be reopened after the recent CA election when a new Constituent Assembly is resumed. This research has convinced us of these women's need for citizenship. Most young women in Nepal in general, especially rural women, need far more assistance from government to be able to improve their opportunities in life and to avoid trafficking than they get. Action is needed especially in access to citizenship, education, work, safe migration and a radical reduction of violence against women. Systematic, structural changes in caste, class and gender are necessary to defeat trafficking and all forms of violence against women: without them, the police and the 
courts will not succeed. The above applies to millions of Nepali women. The needs of returnee women, as we have seen, are greater, and more individual support is required as many lack the help of their families and communities. At the same time lobbying and advocacy on all these fronts are vital.

One confirmation of Shakti Samuha's success in caring, advocacy and campaigning is an international award. Shakti Samuha was selected for the internationally recognized Ramon Magsaysay Award 2013 by the Ramon Magsaysay Award Foundation, Manila, Philippines. Established in 1957, this award is described as Asia's highest honour and is widely regarded as the region's equivalent of the Nobel Prize. The formal conferment of this year's Ramon Magsaysay Awards was at the Cultural Center of the Philippines on August 31st 2013. The slogans of this Foundation, set up by the Rockefeller Foundation, are "Greatness of Spirit. Leadership. Asian Solutions."

\section{Acknowledgements}

To Shakti Samuha and all our interviewees, from Shakti Samuha and stakeholders, as well as to our Advisory Group for its critical support and to the International Organization for Migration (Nepal).

\section{References}

Bennett, Lynn. 2008. 'Policy reform and culture change: Contesting gender, class and culture change in Nepal.' In Anis Ahmad Dani and Arjan De Haan, Inclusive states: Social policy and structural inequalities, pp. 197-224. Washington: The World Bank. 
Bennett, Lynn. 1983. Dangerous wives and sacred sisters: Social and symbolic roles of highcaste women in Nepal. New York: Columbia University Press.

DfID and the World Bank. 2006. Unequal citizens: Gender, caste and ethnic exclusion in Nepal. Printed in Nepal: DFID and the World Bank.

GAATW. 2007. Respect and Relevance: Supporting self-organising as a strategy for empowerment and social change. Bangkok: Global Alliance Against Traffic in Women. Available from http://www.gaatw.org/index.php?option=com content\&id=666\&ltemid=73. Last consulted 5122013.

Poudel, Meena. 2011 Dealing with hidden issues: Social rejection experienced by trafficked women in Nepal. Saarbrucken, Germany: Lambert Academic Publishing.

Rankin, Katharine Neilson. 2004 The cultural politics of markets: Economic liberalization and social change in Nepal. London: Pluto Press.

Rapier-Moore, Rebecca. 2012. Revisiting feminist participatory action research. In Kamala Kempadoo with Jyoti Sanghera and Bandana Pattanaik eds. Trafficking and prostitution reconsidered: New perspectives on migration, sex work and human rights, pp. 231-248. Updated second edition. London, Boulder: Paradigm Publishers.

Richardson, Diane. et al. (under review) 'Becoming Citizens in the "New" Nepal', Citizenship Studies.

Richardson, Diane, Poudel, Meena and Laurie, Nina. 2009. Sexual trafficking in Nepal: constructing citizenship and livelihoods, Gender, Place and Culture Vol. 16, No. 3, pp. 257276. 
Samarasinghe, Vidyamali. 2008. Female sex trafficking in Asia: The resilience of patriarchy in a changing world. London and New York: Routledge.

i Available at http://www.unhcr.org/pages/49c3646c155.html. Last consulted 5122013.

ii Final Report of National Population and Housing Census 2011 published by the Central Bureau of Statistics, December 2012. Available at http://cbs.gov.np/wpcontent/uploads/2012/11/National\%20Report.pdf/ Last consulted 5122013.

iii Post Trafficking Livelihoods in Nepal: Women, Sexuality and Citizenship. Funded by the UK Economic and Social Research Council (ESRC) from September 2009 to April 2012. Grant reference: RES-062-23-1490. Available at http://www.posttraffickingnepal.co.uk/ Last consulted 5122013.

iv Global Alliance Against Traffic in Women. Available at http://www.gaatw.org/. Last consulted 512 2013.

v www.shaktisamuha.org.np. Last consulted 5122013.

vi Available at http://www.indexmundi.com/nepal/demographics profile.html. Last consulted 512 2013.

vii Newars occupy a complex position in the caste system (Rankin 2004, 79-80).

viii Available at http://www.posttraffickingnepal.co.uk. Last consulted 5122013.

ix BBC News, 21 November 2013. Available at http://www.bbc.co.uk/news/world-asia-25030107 Last consulted 5122013.

x Mail Online, India, $24^{\text {th }}$ November 2013. Avalable at http://newsr.in/n/India/74w4fcbsy/Prachanda-wins-bythin-margin-in-Nepal.htm. Last consulted 5122013.

xi BBC News Asia 2811 2013. http://www.bbc.co.uk/news/world-asia-25135595. Last consulted 5122013.

xii The Financial Times, London and New York, 512 2013, p.6. Available from www.ft.com/. Last consulted 5 122013. 